\title{
Distribution and seasonal occurrence of Anopheles minimus in Ishigaki Island, Ryukyu Archipelago, Japan, 1998-1999
}

\author{
Takako TOMA $^{1)}{ }^{2)}$, Ichiro MIYAGI $^{1)}$, Wabyahe L. M. MALENGANISHO ${ }^{1)}$ 3), \\ Hidechika MURAKAMI ${ }^{4)}$, Hitoshi NEROME ${ }^{4)}$ and Masato YONAMINE ${ }^{4)}$ \\ 1) Laboratory of Medical Zoology, School of Health Science, Faculty of Medicine, University of the \\ Ryukyus, Nishihara, Okinawa 903-0215, Japan \\ ${ }^{2)}$ Center for Asia-Pacific Island Studies, University of the Ryukyus, Senbaru 1, Nishihara, \\ Okinawa 903-0213, Japan \\ 3) National Institute for Medical Research, P. O. Box 1462, Mwanza, Tanzania \\ ${ }^{4)}$ Yaeyama Health Center of Okinawa Prefecture, Ishigaki, Okinawa 907-0002, Japan
}

(Received: 4 March 2002; Accepted: 29 March 2002)

Key words: Anopheles minimus, distribution, Ishigaki Island, mosquito, Ryukyu Archipelago, seasonal apperance

\begin{abstract}
A survey was carried out during 1998-1999 to determine the distribution and seasonal abundance of An. minimus Theobald in Ishigaki Island, Ryukyu Archipelago, Japan. Larvae and pupae of An. minimus were collected in 33 of 48 streams in 1998, and 38 of 56 streams in 1999. Immatures of An. minimus were found in almost all the surveyed streams except those in urban areas, fast flowing streams and polluted streams. The abundance of immatures in Fanan and Nishihama Streams, where a lot of the immatures was collected, showed seasonal variation which was positively correlated with water temperature and rainfall. Few immatures were collected during winter season (December to February). As the temperature started to rise in March, the population increased and the density became high from May to August, and October to November, 1999. In Arakawa Stream near urban area, unlike Fanan and Nishihama Streams, the population of $A n$. minimus immatures became biggest from March to April. By light trap method, more than 30 An. minimus adults per night were collected from March to November except May, and the highest number was 228 in July and 321 per night in November, 1999, near Nishihama Stream.
\end{abstract}

\section{INTRODUCTION}

Until 1962, Ishigaki Island and other islands including Iriomote Island of Yaeyama, Ryukyu Archipelago were endemic for malaria which was mainly transmitted by Anopheles minimus Theobald. The epidemic of malaria especially occurred after World War II in 1945 when $53.8 \%$ of the total population in the islands were infected (WHO, 1966; Teruya, 1975; Eshita, 1982). Malaria was eradicated in these islands after initiation of eradication program focusing on, among others, the control of vector mosquitoes using DDT. The program, 
popularly known as Wheeler's plan, enabled the reduction of vectors by 1962 and complete eradication of malaria in that year. However, recent studies by Miyagi and Toma (1978) and Toma et al. (1996) showed a steady increase of An. minimus population in Ishigaki Island.

Anopheles minimus is one of the major vectors of malaria throughout the Oriental Region (Reid, 1968). It exhibits morphological and genetic variations according to geographical locations. Because of these variations it is now considered to be a species complex consisting of several closely related species designated as An. minimus species A, B, C, D (Yuan, 1987; Sucharit, 1988; Baimai, 1989; Green et al., 1990; Harrison et al., 1990). Recently, Somboon et al. (2001) using morphological and genetic analyses revealed the existence of another sibling species in Ishigaki Island, provisionally designated as An. minimus species E. Knowledge of the distribution and relative differences in vector status among the closely related sibling species is an important aspect in control and surveillance of mosquito borne infections. In this paper, the name of An. minimus is used in a broad sense.

Ishigaki Island, like other islands of the Yaeyama Island group, has become famous for tourist attraction. Every year, many people from different countries including malaria endemic areas, visit the island for various purposes. Although malaria is no longer endemic in the island, imported malaria which may be brought by people coming from endemic areas can bring back the infection because of the resurgence of high populations of potential vectors in the Island. Moreover, recently there have been reports of cases of malaria from some places of Korean peninsula which was not endemic for malaria (Strickman et al., 2000). This has raised more concern on the need for continuous surveillance of potential malaria vectors in the area. The main objective of this study was to determine the distribution and seasonal abundance of An. minimus in Ishigaki Island, Ryukyu Archipelago.

\section{Materials AND MethodS}

\section{Study area}

Ishigaki Island is located approximately $700 \mathrm{~km}$ south of Okinawa Island. It has an area of $222.46 \mathrm{Km}^{2}$ with a population of about 43,000 people. The island is generally rural in origin with the exception of the southern part which has business areas and city. Farmlands are scattered all over the island except the southern part. Detailed description of the area has been given by Toma et al. (1996).

\section{Survey procedure}

Using map of 1: 50,000 scale, streams with permanent flowing water were selected for survey. With previous knowledge of the area, efforts were made to search every stream that was possible to reach. The distribution surveys were done for one month from September to October 1998 and again in the same period in 1999. The aim was to understand the distribution pattern of An. minimus larvae in Ishigaki Island and determine the study sites for 
seasonal abundance of the immatures. Different larval stages of An. minimus were collected using a dipper (approximately $500 \mathrm{ml}$ volume) and a small net fastened on a wire frame. At each site, 100 dippings were collected by two persons.

Following this survey, four geographically, ecologically and historically different streams were identified. From these streams, 4 sites were selected for study of seasonal variation of larval appearances. The selected sites were at Nishihama, Fanan, Shiramizu and Arakawa Streams. The areas around Fanan and Shiramizu Streams were malaria endemic in the past. Nishihama Stream showed high density of An. minimus immatures as revealed by the distribution survey, and Arakawa Stream was located near urban area. Survey was carried out twice every month between November 1998 and November 1999. At each stream, 100 dippings were collected by two persons, and the temperature of the water was measured using a thermometer.

Besides larval collection, adult mosquitoes were also collected by light trap method using a black light blue with $50 \mathrm{~W}$. Light traps were placed near cow sheds at the locations selected for larval survey in the three streams, namely, Nishihama, Fanan, and Arakawa streams. Every evening of the two selected days per month the light trap was hung near the cow shed from sunset to sunrise to attract mosquitoes. The collected mosquitoes were sorted out in the early morning to identify $A n$. minimus and An. sinensis and their number was counted.

Weather records on rainfall and ambient temperature were obtained from the meteorological bureau of Ishigaki Island. Water temperature was measured and recorded on site during the survey.

\section{RESULTS}

\section{Weather records}

Fig. 1 shows the average air temperature and total rainfall for the first and second half in each month between September 1998 to November 1999. Generally, air temperature was low

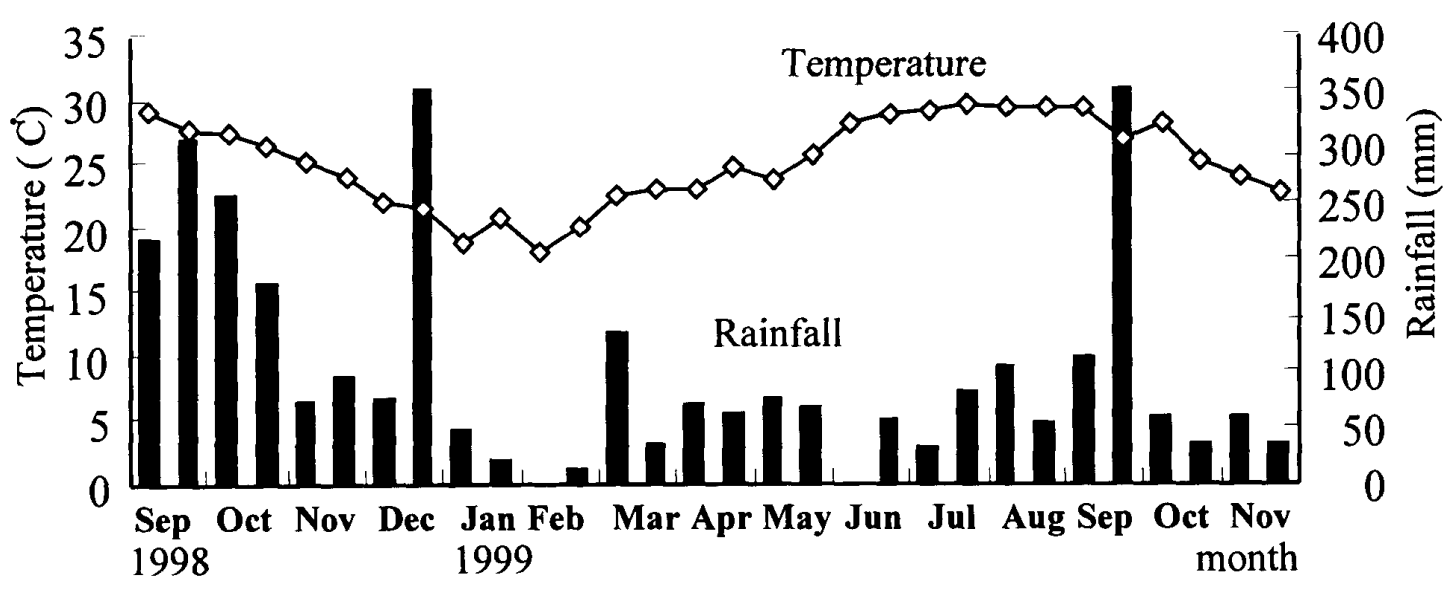

Fig. 1. Temperature and rainfall during the study period (Nov. 1998 to Nov. 1999) in Ishigaki Is., Ryukyu Archipelago. 
Med. Entomol. Zool.

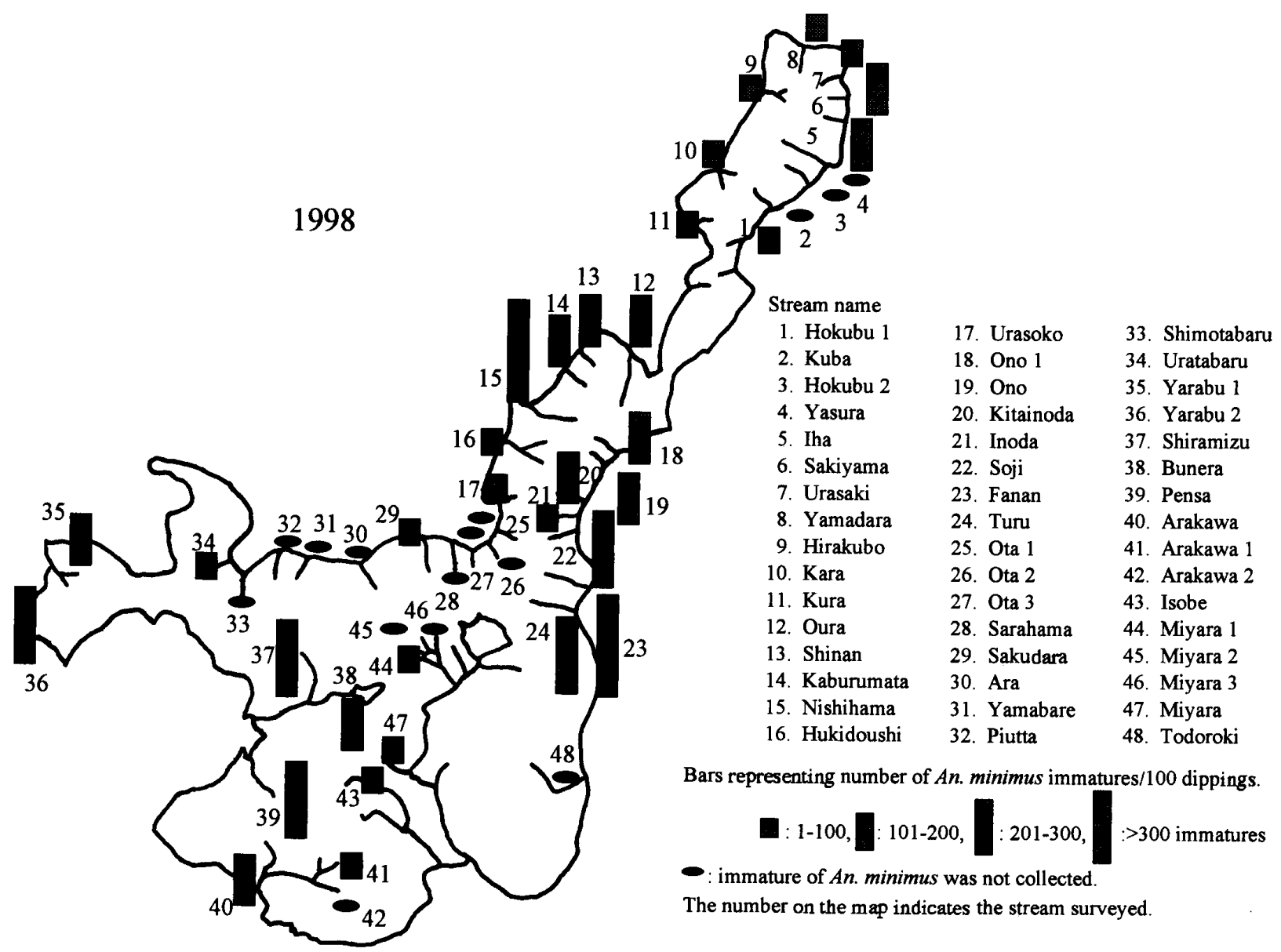

Fig. 2. Distribution and density of Anopheles minimus in 48 streams of Ishigaki Island, Ryukyu Archipelago, 1998.

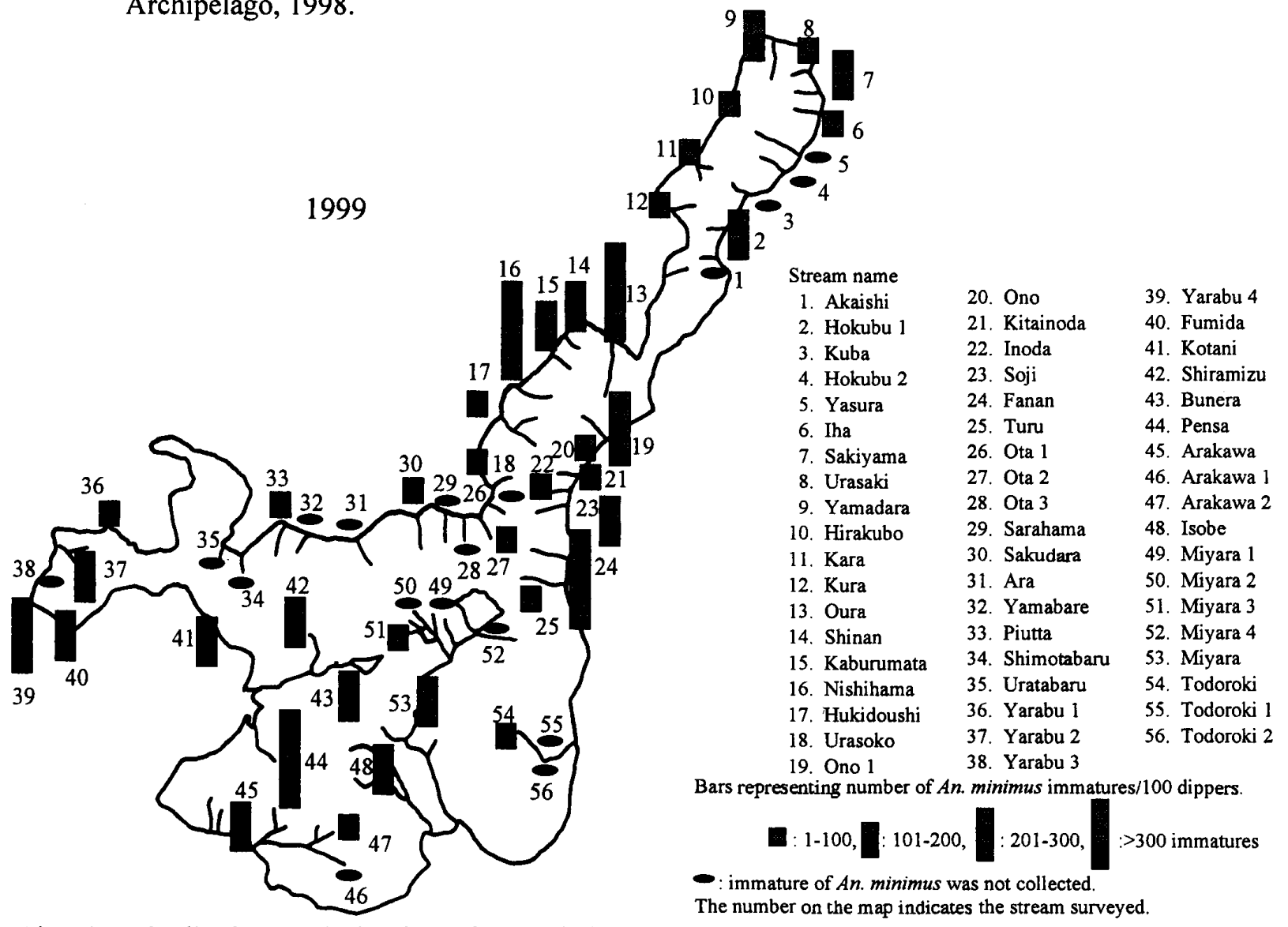

Fig. 3. Distribution and density of Anopheles minimus in 56 streams of Ishigaki Island, Ryukyu Archipelago, 1999. 
in December to February but high in the other of the months. The lowest air temperature $\left(18.1^{\circ} \mathrm{C}\right)$ was recorded in late February 1999 while the highest $\left(29.4^{\circ} \mathrm{C}\right)$ was recorded in late July 1999. The peak rainfall was recorded in late December 1998 and late September 1999. The mean monthly rainfall was low to moderate in the other months except September and October 1998.

\section{Distribution of An. minimus}

In 1998, the survey of immatures was done on 48 streams located at different places of Ishigaki Island. Of the 48 streams surveyed, 33 (69\%) had immatures of An. minimus. Fig. 2 shows the distribution and abundance of An. minimus larvae in different streams of Ishigaki Island. The species was widely distributed throughout the island. Highest larval collections were obtained in streams located in rural areas with minimum human activities. Nishihama (Stream No. 15) (>300 immatures per 100 dippings) and Fanan (No. 23) (>300 immatures) had the highest larval collections. Next in density (201-300 immatures) was in Soji (No. 22), Turu (No. 24), Yarabu 2 (No. 26), and Shiramizu (No. 37) and Pensa Stream (No. 39). The density was low in the central part.

Fig. 3 shows the distribution and abundance of An. minimus immatures in Ishigaki Island between September to October 1999. Of the 56 streams surveyed, $68 \%$ had larvae of $A n$. minimus. The streams having the highest abundance of immatures were Nishihama (Stream No. 16), Fanan (No. 24), Pensa (No. 44), and Oura (No. 13), in which more than 300 immatures were collected by 100 dippings. Next in density (201-300 immatures) was in Ono (No. 19) and Yarabu Stream (No. 39).

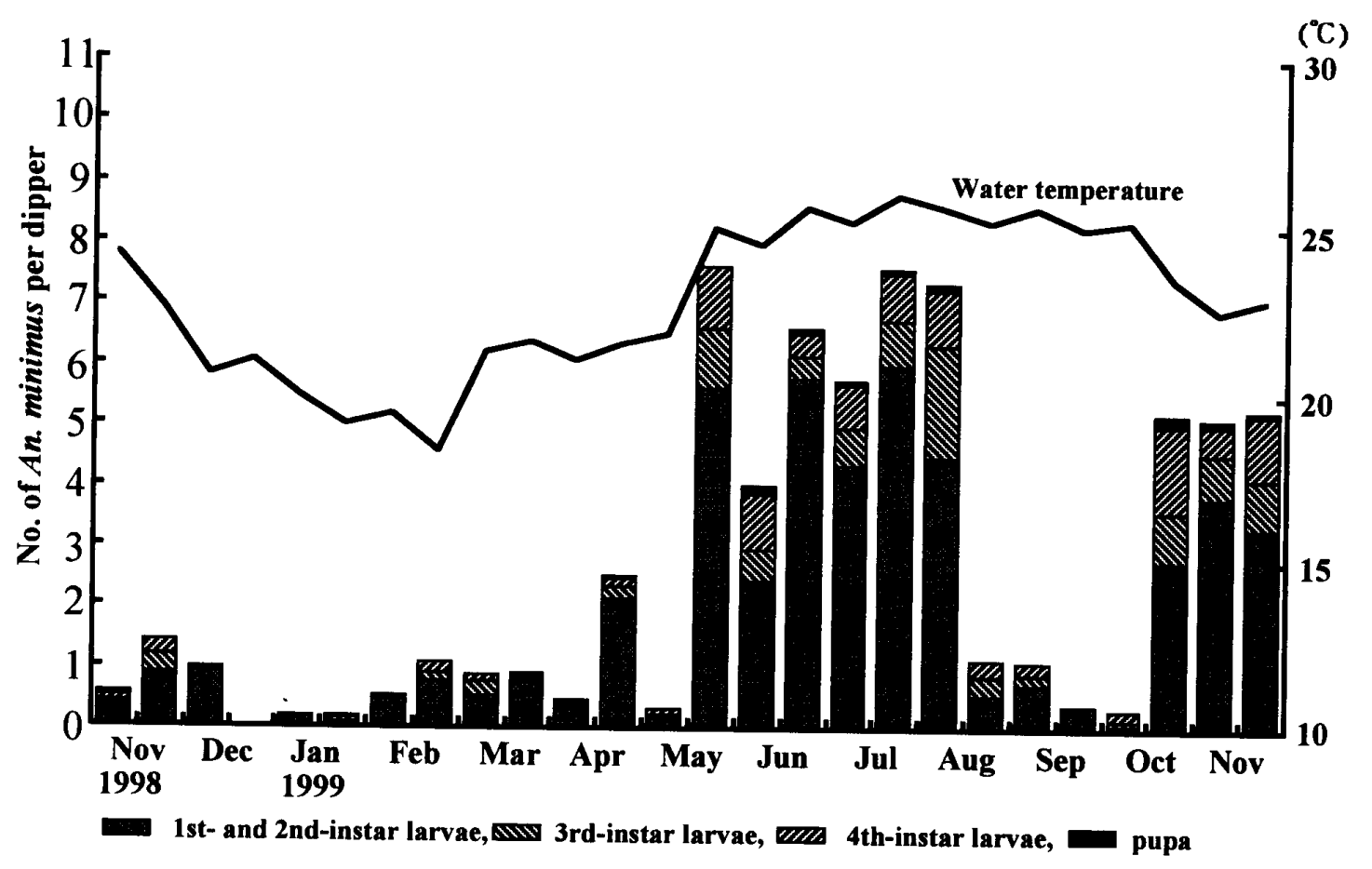

Fig. 4. Seasonal prevalence of Anopheles minimus immatures in Fanan Stream of Ishigaki Island, Ryukyu Archipelago. 
Seasonal prevalence of An. minimus immatures

Fig. 4 shows the water temperature and immature collection in Fanan Stream (No. 24 in Fig. 3). Generally water temperature was low in December to February, and high from the second half of May to the first half of October. The highest water temperature was recorded in late July, $1999\left(26^{\circ} \mathrm{C}\right)$, and the lowest temperature in late February, $1999\left(18.3^{\circ} \mathrm{C}\right)$. There was positive correlation between seasonal variation of water temperature and abundance of immatures in streams. Very few immatures were collected during the coldest months of winter season (December to February), when the water temperature was $18.3-21.0^{\circ} \mathrm{C}$. No larva was collected in late December, 1998. As temperature started to rise in March, the number of larvae collected increased gradually until it reached the peak in late May (7.61 immatures per dipper), 1999. However, there were abnormal deviations of this trend in late May and late October to late November 1999. Very few larvae were collected in May 1999. In the stream, $A n$. sinensis larvae were collected in small number in the season when $A n$. minimus density became high, being 2-3 by 100 dippings (data not shown in the fig.).

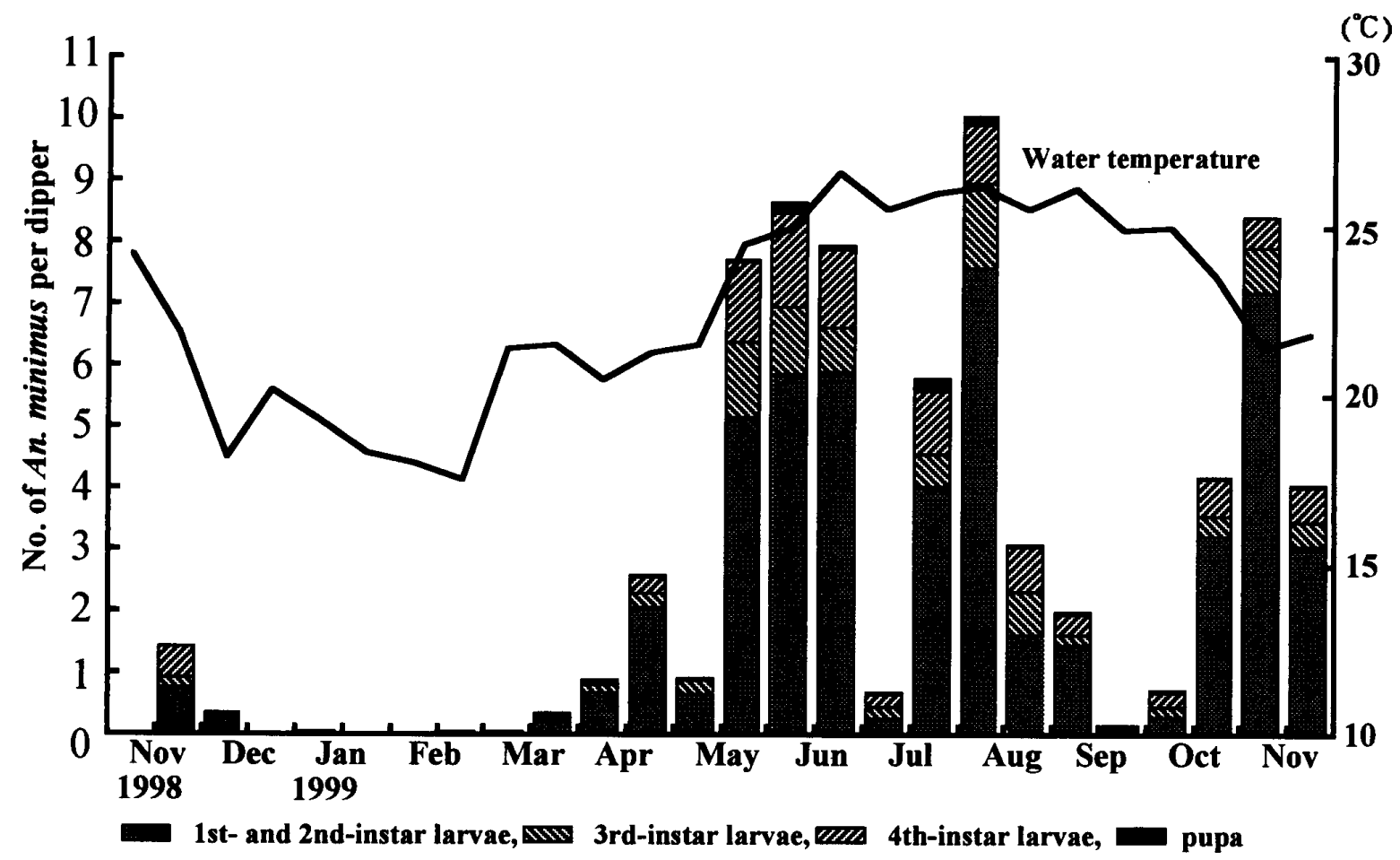

Fig. 5. Seasonal prevalence of Anopheles minimus immatures in Nishihama Stream of Ishigaki Island, Ryukyu Archipelago.

Fig. 5 shows the results of mosquito immature survey in Nishihama Stream (No. 16 in Fig. 3). The abundance of $A n$. minimus immatures followed a seasonal pattern similar to that of Fanan Stream. There were very few larvae collected during winter season when the water temperature was low (below $21^{\circ} \mathrm{C}$ ). No larva was collected in the second half of December 1998. Similarly, very few larvae (0.01-0.04 per dipper) were collected in January through the first half of March 1999. The population of larvae increased gradually after the second half of March to reach the maximum in early August 1999 (10.02 immatures per dipper), when the 
temperature was also at its peak $\left(26.2^{\circ} \mathrm{C}\right)$. Exceptions were in early May and early July 1999 when an unexpectedly low number of larvae was collected. In the stream, An. sinensis larvae were collected in small number when An. minimus density became high, being 2-3 by 100 dippers (data not shown in the fig.).

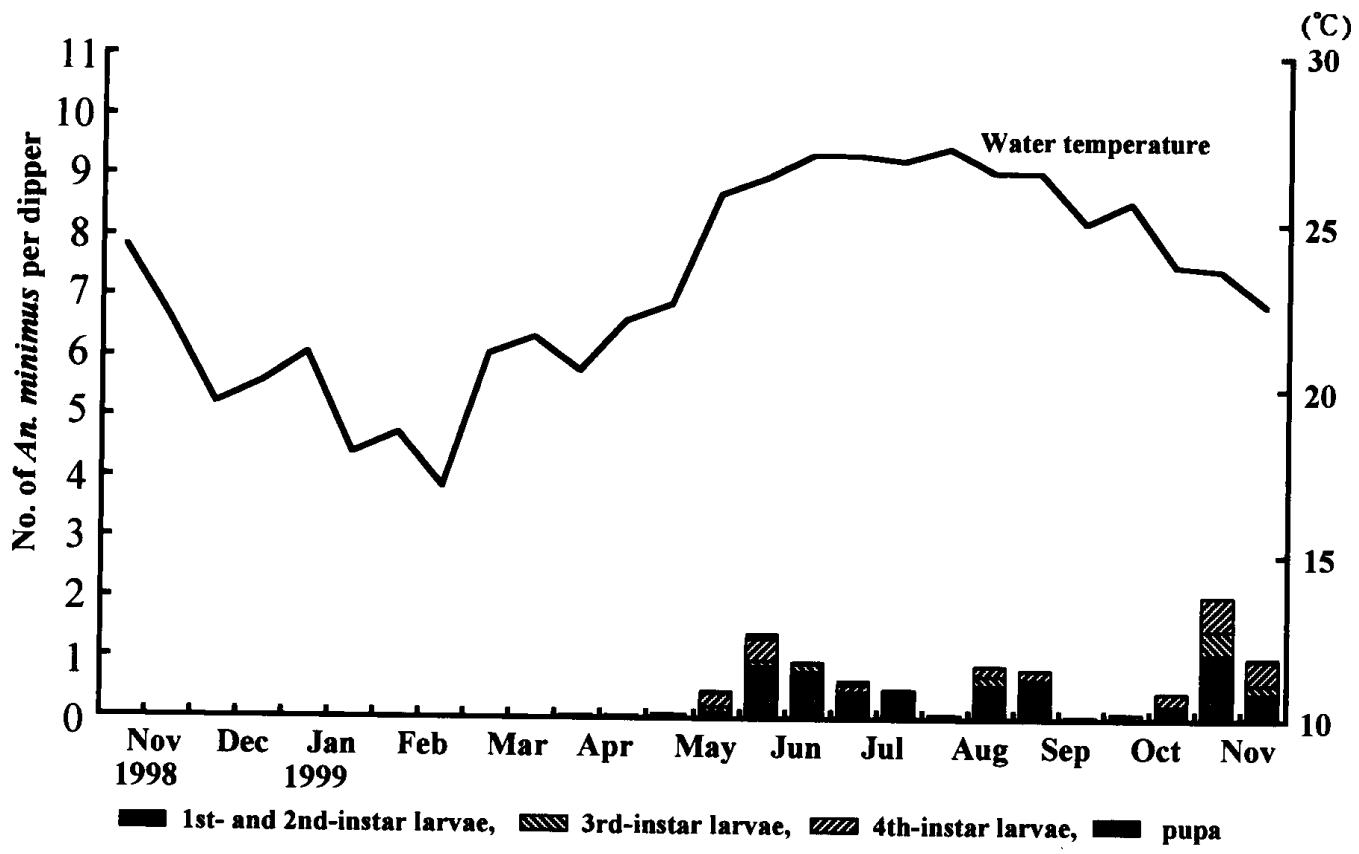

Fig. 6. Seasonal prevalence of Anopheles minimus immatures in Shiramizu Stream of Ishigaki Island, Ryukyu Archipelago.

Fig. 6 shows the results of larval survey at Shiramizu Stream (No. 42 in Fig. 3). Immature An. minimus was not collected from November, 1998 to the first half of March, 1999. The water temperature in winter season was from 18.3 to $21.4^{\circ} \mathrm{C}$. In the first half of

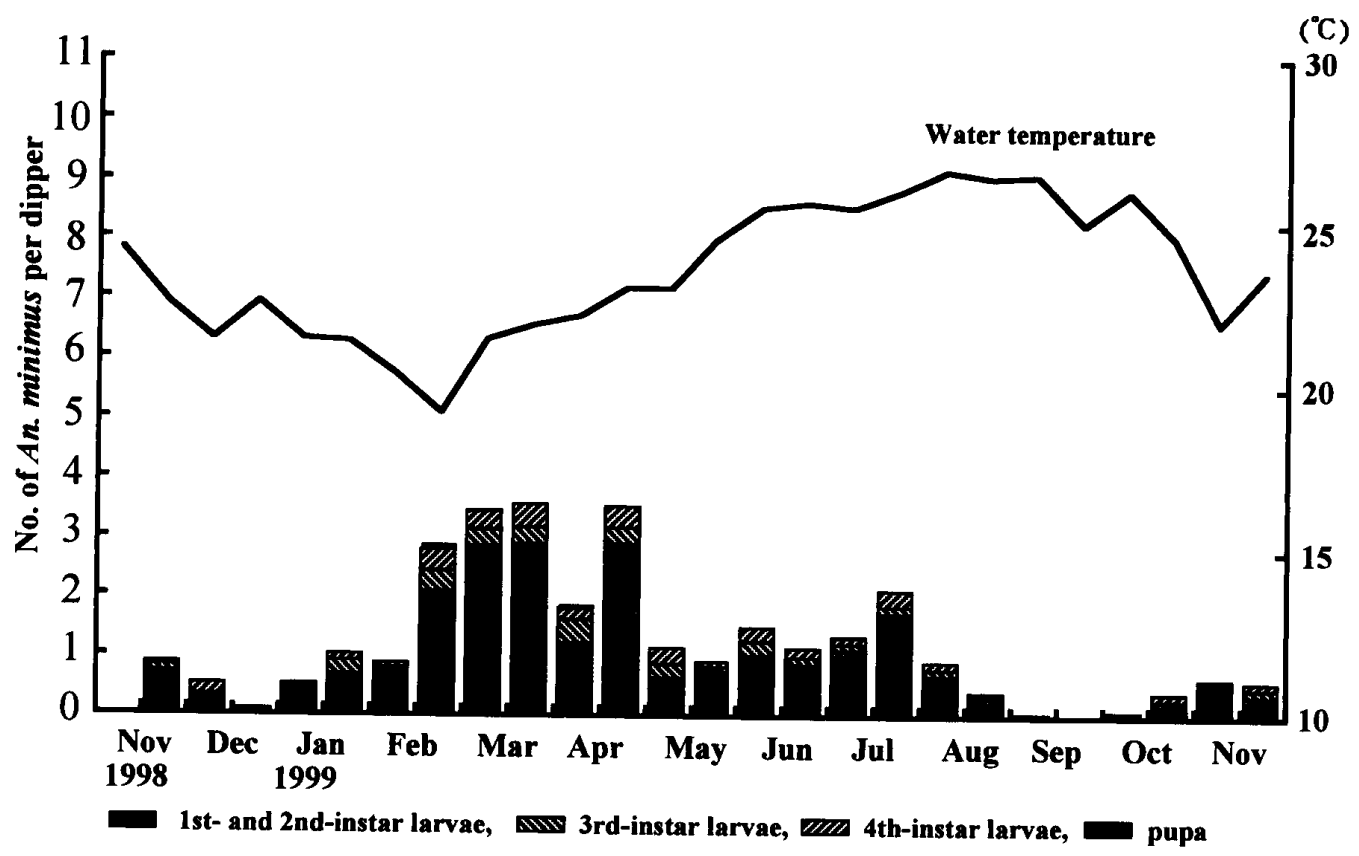

Fig. 7. Seasonal prevalence of Anopheles minimus immatures in Arakawa Stream of Ishigaki Island, Ryukyu Archipelago. 
June and November, 1999, the number of immatures was 1.41 and 2.07 per dipper, respectively.

The result of immature survey in Arakawa Stream is shown in Fig. 7 (No. 47 in Fig. 3). This survey was done near urban area. Unlike other mentioned streams, the abundance of larvae in this stream did not follow the seasonal pattern of water temperature. The temperature in winter season (December to February) was 19.2 to $22.6^{\circ} \mathrm{C}$. Small number of larvae was recorded in late December, 1998, but it increased steadily in January 1999 until it peaked in April (3.54 immatures per dipper) after which it started to decrease even in summer days of early August when the temperature was highest $\left(26.6^{\circ} \mathrm{C}\right)$.

Seasonal appearance of An. minimus adults

Fig. 8 shows the seasonal abundance of adult Anopheles mosquitoes collected near Fanan Stream. There were few An. minimus adult mosquitoes throughout the year, almost none in winter season. Most of the mosquitoes were caught after March 1999, and comprised mainly An. sinensis Wiedemann ( $90 \%)$. The highest number of $A n$. minimus was 80 per night in the first half of June, 1999.

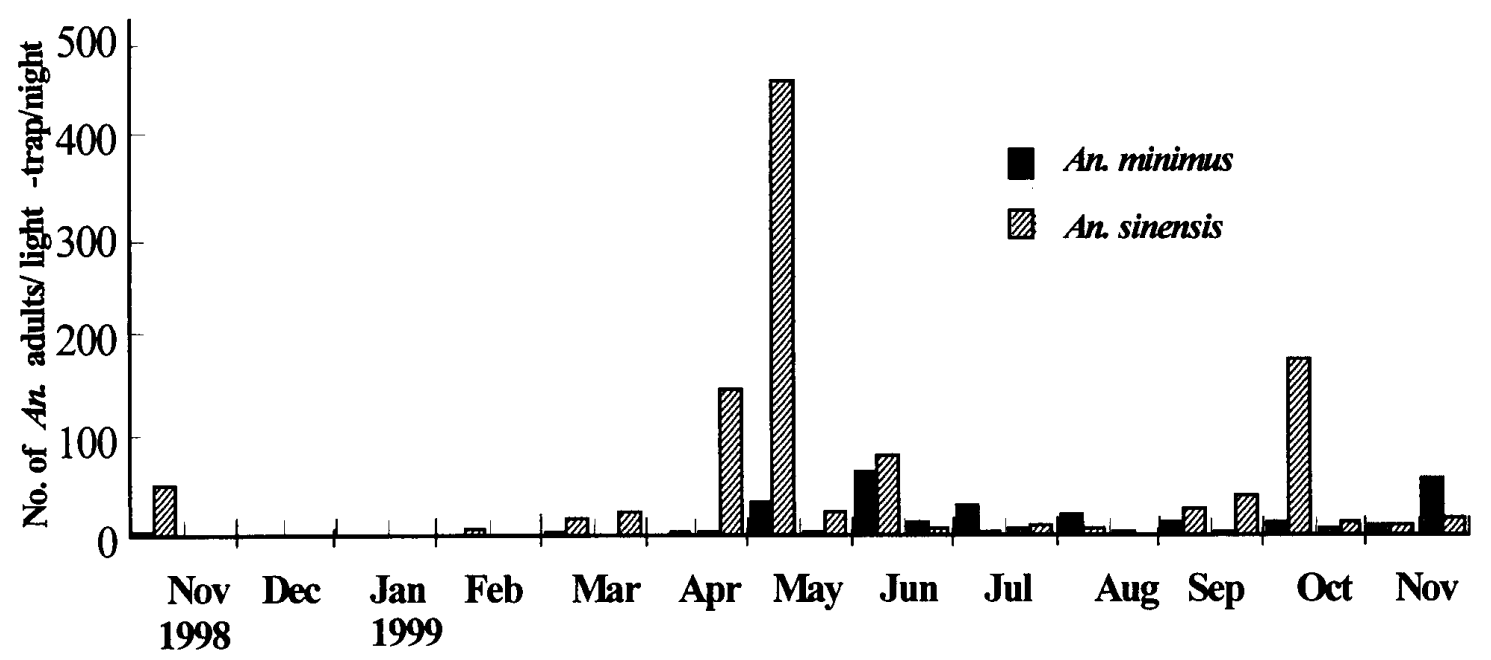

Fig. 8. Number of Anopheles minimus and An. sinensis adults collected by light-trap near Fanan Stream of Ishigaki Island, Ryukyu Archipelago.

Fig. 9 shows the seasonal appearance of adult An. minimus mosquitoes in Nishihama area. Few mosquitoes were collected when water temperature was low (November 1998 to February 1999). As temperature started to rise in March 1999, the abundance of mosquitoes also increased. More than 30 adults per night were collected from March to November 1999 except May. The number of An. minimus was 228 and 321 adults per night in the first half of July and November, respectively. Both An. minimus and An. sinensis were collected throughout this period. 


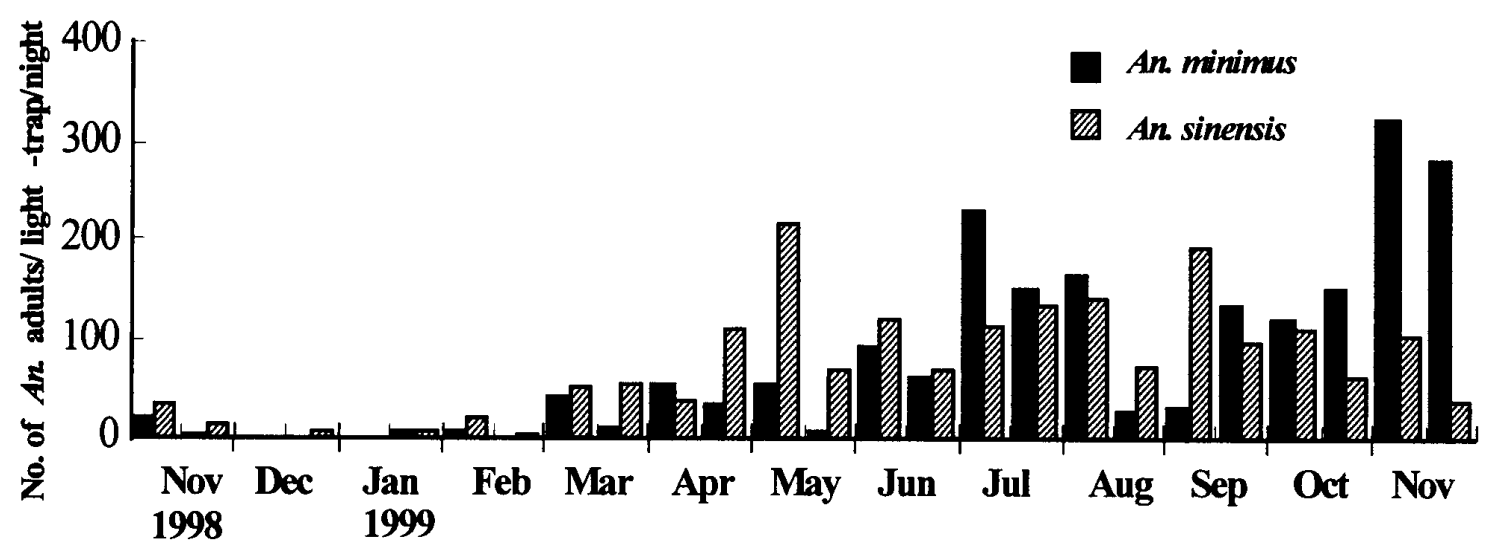

Fig. 9. Number of Anopheles minimus and An. sinensis adults collected by light-trap near Nishihama Stream of Ishigaki Island, Ryukyu Archipelago.

Fig. 10 shows the seasonal occurrence of anopheline mosquitoes at Arakawa area. Very few An. minimus were collected from this site throughout the year. Most of the mosquitoes were An. sinensis. The highest collection was in April (2 An. minimus and 559 An. sinensis per night) and May ( 1 and 454 per night), 1999 at the start of rising temperature. For $A n$. minimus, only 1 or 2 adults were collected in the other months.

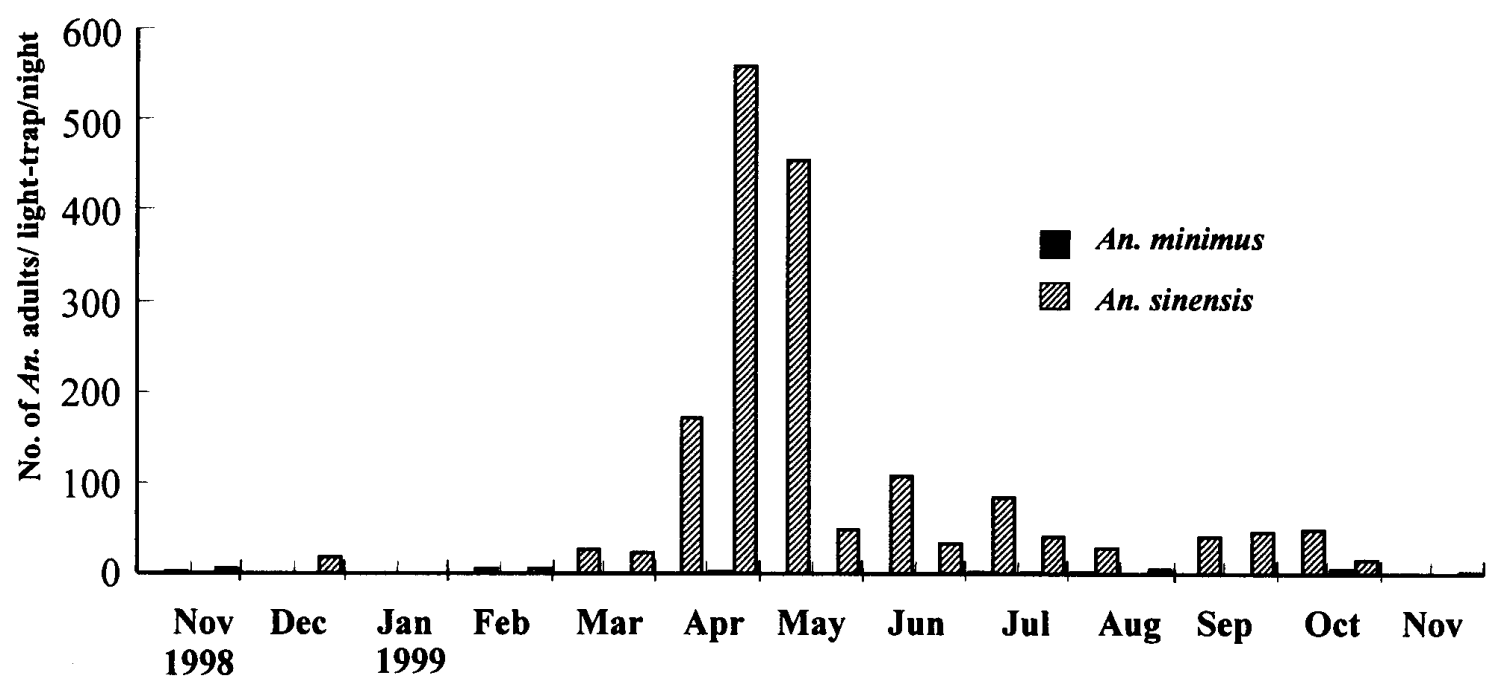

Fig. 10. Number of Anopheles minimus and An. sinensis adults collected by light-trap near Arakawa Stream of Ishigaki Island, Ryukyu Archipelago.

\section{Discussion}

Anopheles minimus is widely distributed from South-eastern Asia to as far as Miyako Island which appears to be the northern geographical limit of this species (Miyagi et al., 1996). It normally breeds along the banks of unpolluted streams (Toma and Miyagi, 1986). An. minimus was considered to be the primary vector of falciparum malaria in Ishigaki Island during and after World War II. Transmission of malaria was drastically interrupted after 
introduction of DDT residual spray as a component of malaria eradication program (WHO, 1966; Sakihara et al., 1994 ). By 1962 the density of An. minimus was significantly reduced along with malaria infections in human (WHO, 1966; Miyagi et al., 1996). Populations of $A n$. minimus started to appear again and increase in the island after the stoppage of the extensive use of DDT but malaria remained eradicated. Studies by Miyagi and Toma (1978) in 1975-1977 and Toma et al. (1996) in 1990-1994 showed that An. minimus larvae started to increase especially in forested streams of the north and eastern areas. It was therefore recommended that regular surveys on distribution and dynamics of Anopheles larvae should be done on the island.

In this survey for distribution of An. minimus in 1998 and 1999, it became clear that the species was widely distributed throughout the island. About $70 \%$ of the streams harbored $A n$. minimus, similar to the findings of Toma et al. (1996). The immature of this species was not present in the streams (No. 42 in Fig. 2; No. 46 in Fig. 3) in urban areas where human activities have interrupted their natural breeding habitat. Furthermore, An. minimus being a stream breeder in unpolluted water, was not found in streams located in areas with high agricultural activities (Nos. 45 and 46 in Fig. 2; Nos. 49, 50 and 52 in Fig. 3) or with domestic drainage effluents ( No.31 in Fig. 2; No. 32 in Fig. 3). According to Toma et al. (1996), these polluted areas were previously found to have comparative high values of $\mathrm{pH}$, chemical oxygen demand (COD), $\mathrm{NH}_{4}-\mathrm{N}, \mathrm{NO}_{3}-\mathrm{N}$ and low value of dissolved oxygen (DO). In our survey, immature of An. minimus was not found in streams (No. 30 in Fig. 2; No. 31 in Fig. 3) whose water had high velocity, and in streams (No.48 in Fig. 2; Nos. 55, 56 in Fig. 3) which had a concrete bed and bank. The immature also was not found in streams (Nos. 2, 3 and 4 in Fig. 2; Nos. 1, 3, 4 and 5 in Fig. 3) with small volume, and streams that sometimes dried up. The present results also supported previous finding of Toma et al. (1996) on the distribution of immatures of An. minimus in Ishigaki Island.

Four (Fanan, Nishihama, Arakawa and Shiramizu) of 56 streams surveyed for distribution of An. minimus were selected to elucidate the seasonal prevalence of this species on Ishigaki Island. The areas around Fanan and Shiramizu Streams were malaria endemic in the past. Nishihama showed high density of the immatures in the distribution survey. Arakawa Stream, with An. minimus immatures in low density, is near to urban area of Ishigaki Island. The average immature density from November 1998 to November 1999, was 2.6 per dipper in Fanan, 2.7 in Nishihama, 1.2 in Arakawa and 0.37 in Shirahama. The value obtained by Toma et al. (1996) was 3.5 in 1993 and 6.2 in 1994 in Fanan, and 2.2 in 1993 and 3.8 in 1994 in Nishihama. The values of Fanan and Nishihama in this survey are similar to those of 1993 and 1994.

This study showed marked seasonal variation of immatures and adults which was correlated with rainfall and temperature. The population of larvae and adults of An. minimus decreased during the cold season of December to February when the water and air temperatures also dropped. The number of immatures collected was high when water 
temperature became high, especially in Fanan and Nishihama. The fluctuation of the immature population in Fanan Stream was similar to that of Nishihama Stream. A lot of immatures (4-10.0 per dipper) were collected from the second half of May to August, 1999, and the second half of October to November, except the second half of August to the first half of October when high rainfall occurred before the collection day. High rainfall had a negative influence on both immatures and adults of An. minimus by flooding and flashing away immatures and adults, respectively. In previous survey (Toma et al., 1996), immature population peaked in September in 1993, and July in 1994 in Fanan and Nishihama. The density of immature in November 1998 was quite different from November 1999. During winter season, the density was low, being 0.48 per dipper in Fanan and 0.068 in Nishihama. This difference might be related to the water temperature, $19.7^{\circ} \mathrm{C}$ in Fanan and $18.6^{\circ} \mathrm{C}$ in Nishihama during winter season. As Fanan and Nishihama areas had paddy and sugar cane fields, the adults of An. minimus were collected with An. sinensis. The number of An. minimus adults collected in Nishihama was bigger than that of Fanan. This difference in number of the adults collected might be due to the distance from larval breeding place to the adult collection site that was important for the females to get blood source. By mark-release-recapture of adult An. minimus (Tsuda et al., 1999), flight distance was found to be more than $1 \mathrm{Km}$. The distance from breeding and collection sites in Nishihama $(1 \mathrm{Km})$ was shorter than in Fanan.

The seasonal appearance of An. minimus immatures in Arakawa Stream was different from those of Fanan and Nishihama. The highest population of An. minimus in Arakawa occurred in the first half of March to the second half of April, and the density in winter was 0.97 per dipper, the highest in the 4 streams surveyed. The water temperature in winter in Arakawa $\left(21.1^{\circ} \mathrm{C}\right)$ was highest among the 4 streams. A possible cause of these results might be differences in condition of water temperature. The water coming out from the ground was comparatively warmer than that of the other streams. Therefore even during winter season the water was warm enough for An. minimus immatures to breed. The width of the stream is narrow and the length is short, and the water volume is small. In the season when many immatures were collected in Fanan and Nishihama, the density in Arakawa was low. From these results, the immatures might concentrate in Arakawa during winter, and dispersed to good breeding habitats in other areas near the stream. Hence many immatures were breeding in the stream near to urban area during winter season. In Arakawa area, a cow shed that was a collection site for adults, was situated in open area without vegetation. Only few An. minimus adults were collectd. Many factors such as distance, environmental condition, and geographical conditions between breeding and adult collection sites, might influence the number.

In Shiramizu Stream, the density of An. minimus was low. During winter season, there was no immature. The water temperature was relatively low, being $19.0^{\circ} \mathrm{C}$. The highest density was 2.07 per dipper. This stream passed through the forest, and had concrete bottom and edges without plants. It was wide and fast flowing, hence difficult for mosquito to breed. 
The area around Shiramizu Stream was malaria endemic in the past. The decrease in the density in this study might be related to the stream condition, i.e. the edge and bottom of the stream was changed to be concrete.

Agricultural activities have increased considerably in recent years in this Island. The central part has been turned into sugar cane farms. In this area, population of An. minimus has decreased probably due to increased pollution by chemicals used in the farms. However $A n$ sinensis was found in paddy areas. Anopheles saperoi, a stream breeder, was not found at any of the streams surveyed in this study as in previous study (Toma et al., 1996). Recent studies by Higa et al. (1998) showed absence of An. saperoi ohamai (Ohama, 1947). The other areas near the forested hillsides on the eastern part of the island contained livestock farms. The number of cattle has increased from 8,236 in 1978 to 19,396 in 1993 (Toma et al., 1996) and about 27, 200 in 2000. These areas such as Fanan, Nishihama and Oura (No. 19 in Fig. 3) had higher number of immatures of An. minimus. The increase of cattle and probably other livestock such as pigs near the streams enhanced supply of blood for mosquito to feed to facilitate oviposition. This in turn resulted in the observed increase of both immatures and adults of An. minimus.

The spatial and temporal distribution of $A n$. minimus in Ishigaki Island is probably a result of many other abiotic and biotic factors acting together. Apart from temperature and aquatic habitats, sources of blood to initiate oviposition in female mosquitoes may determine the abundance and distribution of mosquitoes in an area. During and after World War II there were high density of $\mathrm{An}$. minimus probably because of the easy availability of blood source from humans. At that time most of the people had unprotected houses for mosquito entry and spent most of their time in captivity in the forest where they were frequently bitten by mosquitoes in their search for blood to initiate oviposition.

Ishigaki Island is now receiving many travelers each year. According to the recent official statistics of Ishigaki city office 599,343 tourists visited the island between January and December 2000. The island has a permanent population of about 43,000 inhabitants. Almost all of them live in the city area on the southern part of the island where An. minimus is not abundant and also the houses are well protected against mosquito entry. Nevertheless, the other areas of the island have scattered housing facilities for tourists. Some travelers camp out on beaches during summer vacations and these facilities have poor means of mosquito protection. This, in time, may pose a threat to transmission of imported malaria in this area. With global warming, it is estimated an abnormal abundance of the vector mosquitoes and their frequent migrations to the north. Therefore there is a need for continual surveillance of both malaria infections and vectors in this island.

\section{ACKNOWLEDGEMENT}

The authors wish to thank Dr. Z. Shimabukuro and Mr. Y. Asato of Yaeyama Health 
Center of Okinawa Prefecture, Ishigaki city and Mr. T. Kishimoto and Mr. T. Nakasone of Prefectural Institute of Health and Environment, Okinawa Prefecture, Okinawa for cooperation in the field study. The authors also wish to thank Dr. Yong Hoi Sen, Faculty of Science, University of Malaya, for reading the manuscript and for useful comments. This study was supported by Grant-in-Aid for Scientific Research on Priority Areas (No. 11147228) from the Ministry of Education, Science, Culture and Sports, and Grant for Special Program on Promotion of Regional Health, 1998-2001, Ministry of Health and Welfare, Japan.

\section{REFERENCES}

Baimai, V. 1989. Speciation and species complexes of the Anopheles malaria vectors in Thailand. In: Proceeding of the 3 rd conference on malaria research, Thailand. 1989. 146-162.

Eshita, Y. 1982. Historical review of malaria and eradication measures in the Ryukyu Archipelago. Kankyo Eisei, 29: 26-34 (In Japanese).

Green, C., Gass, R. F., Munstermann, L. E. and Baimai, V. 1990. Population-genetic evidence for two species in Anopheles minimus in Thailand. Med. Vet. Entomol., 4: 25-34.

Harrison, B. A., Rattanarithikul, R., Peyton, E. L. and Mongkolpanya, K. 1990. Taxonomic changes, revised occurrence records and notes on the Culicidae of Thailand and neighboring countries. Mosq. Syst., 22: 196-227.

Higa, Y., Toma, T., Miyagi, I., Malenganisho, W. L. M. and Takagi M. 1998. Morpho-taxonomical studies on two subspecies of Anopheles saperoi (Diptera:Culicidae) from the Ryukyu Archipelago, Japan. Med. Entomol. Zool., 49: 207-216.

Miyagi, I. and Toma, T. 1978. Studies on mosquitoes in Yaeyama Island: 1. Appearances of anopheline mosquitoes, especially Anopheles minimus minimus Theobald in Ishigakijima and Iriomotejima. Jpn. J. Sanit. Zool., 29: 243-250 (in Japanese with English summary).

Miyagi, I., Toma, T., Malenganisho, W. L. M. and Uza, M. 1996. Historical review of mosquito control as a component of malaria eradication program in the Ryukyu Archipelago. Southeast Asian J. Trop. Med. Public Health, 27: 498-511.

Ohama, S. 1947. Epidemiological study of malaria in Yaeyama. No.2 report. On an anopheline mosquito Anopheles ohamai (Ishigaki Island) 1947, which is a newly found in Ishigaki Island. Rec. Public Health Dep. Yaeyama Prov. Govt., 4: 1-15 (Japanese mimegraph).

Reid, J. A. 1968. Anopheline mosquitoes of Malaya and Borneo. Stud. Inst. Med. Res. Malaysia, 31: $1-520$.

Sakihara, S., Nishi, K., Toyama, F., Uza, M. and Taira, K. 1994. A revised analysis of malaria epidemic in Ryukyu Islands during World War II. Jpn. J. Health Hum. Ecol., 60: 67-84 (in Japanese with English summary).

Somboon, P., Walton, C., Sharpe, R. G., Higa, Y., Tuno, N., Tsuda, Y. and Takagi, M. 2001. Evidence for a new sibling species of Anopheles minimus from the Ryukyu Archipelago, Japan. J. Am. Mosq. Cont. 
Assoc., 17: 98-113.

Strickman, D., Miller, M. E., Kim, H. C. and Lee, K. W. 2000. Mosquito surveillance in the demilitarized zone, Republic of Korea, during an outbreak of Plasmodium vivax malaria in 1996 and 1997. J. Am. Mosq. control Assoc., 11: 377-378.

Sucharit S. 1988. Research in taxonomic classification of Anopheles minimus. Southeast Asian J. Trop. Med. Pub. Hlth., 19:86.

Teruya, K. 1975. Notes on the important infectious diseases in Okinawa Prefecture after the World War II: Medical history of Okinawa. Ann. Rep. Okinawa Prefecture Inst. Public Health, 9: 175-217 (In Japanese).

Toma, T. and Miyagi, I. 1986. The mosquito fauna of the Ryukyu Archipelago with identification keys, pupal descriptions and notes on biology, medical importance and distribution. Mosq. Syst., 18: 1-109.

Toma, T., Miyagi, I., Malenganisho, W. L. M., Tamashiro, M., Takagi, M., Higa, Y., Tsuda, Y., Sugiyama, A. and Ishak, H. 1996. Distribution and seasonal prevalence of the malaria vector mosquito, Anopheles minimus in Ishigaki Island, Ryukyu Archipelago, Japan, 1990 - 1994. Jpn. J. Sanit. Zool., 47: 63-72.

Tsuda, Y., Takagi, M., Toma, T, Sugiyama, A. and Miyagi, I. 1999. Mark-release-recapture experiment with adult Anopheles minimus (Diptera: Culicidae) on Ishigaki Island, Ryukyu Archipelago, Japan. J. Med. Entomol., 36: 601-604.

World Health Organization, 1966. Report of the WHO evaluation team on malaria eradication in the Ryukyu Islands. WPR/419/65/ 1-53.

Yuan, Y. 1987. Studies on the two forms of Anopheles (Cellia) minimus Theobald, 1901 in China (Diptera: Culicidae). Mosq. Syst., 19:143-145. 